\title{
MULHERES CUIDADORAS DE HOMENS COM DOENÇA RENAL CRÔNICA: UMA ABORDAGEM CULTURAL
}

\author{
Elisabeth Gomes da Rocha Thomé1, Dagmar Elisabeth Estermann Meyer ${ }^{2}$
}

\footnotetext{
${ }^{1}$ Doutoranda do Programa de Pós-Graduação em Enfermagem da Universidade Federal do Rio Grande do Sul (UFRGS). Professora Assistente III do Departamento de Enfermagem Médico-cirúrgica da Escola de Enfermagem da UFRGS. E-mail: bethgomesbr@yahoo.com.br

${ }^{2}$ Doutora em Educação. Professora Associado III na Faculdade de Educação da UFRGS. Pesquisadora CNPq. E-mail: dagmaremeyer@yahoo.com.br
}

\begin{abstract}
RESUMO: Este artigo discute e problematiza processos de cuidar de homens com doença renal crônica, nos quais se constituem identidades cuidadoras. Desdobra-se de uma pesquisa qualitativa, realizada na Clínica de Hemodiálise do Hospital de Clínicas de Porto Alegre-RS. Neste trabalho, analisam-se entrevistas semiestruturadas realizadas com dez cuidadoras, na perspectiva da teorização cultural pós-crítica. Dessas entrevistas focalizam-se: impactos na saúde física e mental, formas de lidar com a dependência crescente do homem do qual cuidam, reconfigurações de seus relacionamentos afetivos, sentimentos de esperança/desesperança, alegria/raiva, dentre outros. As análises realizadas permitem argumentar que, em suas falas, as cuidadoras mobilizam representações de gênero que instituem o cuidado como essência e como destino de mulheres, ao mesmo tempo em que, no processo de cuidar, elas ressignificam a si mesmas e ao seu meio social e cultural.
\end{abstract}

DESCRITORES: Insuficiência renal crônica. Cuidado. Cultura. Identidade.

\section{WOMEN CAREGIVERS FOR MEN WITH CHRONIC KIDNEY DISEASE: A CULTURAL APPROACH}

\begin{abstract}
This article discusses and outlines the processes of giving care to men with chronic kidney disease, in which care-giving identities are constituted. This study has derived from qualitative research carried out at the Hemodialysis Sector in the Clinical Hospital (Hospital de Clínicas) in Porto Alegre, RS, Brazil. Semi-structured interviews were carried out among ten caregivers and then analyzed from a post-critical cultural theory perspective. From these interviews, the following topics received focus: impacts on physical and mental health; ways of dealing with men's growing dependence; reconfiguration of affectionate relationships; feelings of hope/ hopelessness and/or joy/anger; among others. Speech analyses reveal the argument that caregivers mobilize gender representations that institute care as both a feminine essence and the fate of women. At the same time, caregivers redefine themselves and their social and cultural environments through their respective care processes.
\end{abstract}

DESCRIPTORS: Chronic kidney disease. Care. Culture. Identity.

\section{MUJERES CUIDADORAS DE HOMBRES CON ENFERMEDAD RENAL CRÓNICA: UN ENFOQUE CULTURAL}

\begin{abstract}
RESUMEN: En este artículo se discute y problematizan los procesos del cuidado de hombres con enfermedad renal crónica, durante los cuales se constituyen identidades cuidadoras. Surge de una investigación cualitativa, realizada en la Clínica de Hemodiálisis del Hospital de Clínicas de Porto Alegre-RS, y aquí se analizan entrevistas semiestructuradas, realizadas a diez cuidadoras, bajo el punto de vista de las teorías culturales poscríticas. En esas entrevistas se enfocan: impactos en la salud física y mental, formas de relacionarse con la creciente dependencia del hombre cuidado, reconfiguraciones de sus relaciones afectivas, sentimientos de esperanza/desesperanza, alegría/rabia, entre otros. Los análisis realizados permiten argumentar que en sus respuestas las cuidadoras movilizan representaciones de género que instituyen el cuidado como esencia y destino de la mujer, al mismo tiempo que, en el proceso de cuidar, se resignifican a sí mismas y a su medio cultural y social.
\end{abstract}

DESCRIPTORES: Insuficiencia renal crónica. Cuidado. Cultura. Identidad. 
"A experiência da felicidade, ou de sua falta, é uma vivência bastante concreta. Mas ela é índice de si mesma, isto é, não se deixa medir por nada fora dela, e ao mesmo tempo está em estreita relação com tudo aquilo pelo que buscamos dimensioná-la, como uma espécie de ‘bússola existencial', que nos dá o norte sem ser o norte. A felicidade nunca deixa de fazer notar sua falta e, pela sua ausência, algo que nos está faltando."1:551

\section{O TEXTO EM CONTEXTO: UM MODO DE VER}

Este artigo desdobra-se da pesquisa que constitui a tese de doutorado de uma das autoras. $\mathrm{Na}$ tese, são analisadas trajetórias identitárias de homens adultos diagnosticados como doentes renais crônicos que se encontram em tratamento hemodiálitico, e o trabalho de campo permitiu delinear a centralidade de mulheres cuidadoras nessas trajetórias. Foi possível perceber que as relações de cuidado aí constituídas reconfiguram, de forma ampla, formas de sentir e de viver das mulheres, ${ }^{2-3}$ que se veem colocadas na contingência de lidar com esse processo de adoecimento. A isso nomeamos 'tornar-se' cuidadora. Esse processo de 'tornar-se' uma identidade - cuidadora, neste caso - envolve um complexo de forças e de processos de aprendizagem que atravessa todas as dimensões, situações e relações com as quais seres humanos são confrontados ao longo de suas vidas.

O objetivo deste artigo é, então, descrever e problematizar, do ponto de vista dos estudos culturais e dos estudos de gênero pós-críticos, algumas das aprendizagens culturais efetivadas por essas mulheres no processo de 'tornar-se cuidadora' de homens doentes renais crônicos. Partimos das seguintes questões: como mulheres cuidadoras de doentes renais crônicos vivenciam esse processo de cuidar? O que elas aprendem sobre si mesmas, sobre o outro e sobre a doença? Como essas aprendizagens redimensionam suas identidades na vida cotidiana?

Na perspectiva teórica adotada, alguns pressupostos são fundamentais para delimitar nossos 'modos de ver' na análise proposta. Assim, assumimos que cultura é um campo de luta e contestação em que se produzem tanto os sentidos que atribuímos à doença renal crônica e aos cuidados que ela demanda, por exemplo, quanto identidades e diferenças culturais. Consideramos que "a identidade cultural ou social é o conjunto daquelas características pelas quais os grupos sociais se definem como grupos: aquilo que eles são. Aquilo que eles são, entretanto, é inseparável daquilo que eles não são, daquelas características que os fazem diferentes de outros grupos". ${ }^{\text {:46 }}$ Os processos de diferenciação - entre saúde e doença, entre homens e mulheres e entre quem cuida e quem é cuidado, por exemplo - em que identidades são formadas envolvem relações de poder e estão intrinsecamente relacionados com processos de significação cultural em torno do 'nós' e do 'eles'. Identidade não é, nessa perspectiva, uma identidade fixa, unitária e acabada, mas está sempre em um processo de 'tornar-se' uma identidade dentro de certos grupos de significados, selecionados a partir de uma diversidade infinita de sentidos potenciais, produtos de uma situação real.

Entendemos, ainda, que gênero funciona como um dos organizadores da estrutura social e da cultura, englobando todos os processos pelos quais a cultura constrói e distingue sujeitos femininos e masculinos. Nessa perspectiva, o gênero é 'aprendido' pela via da cultura e inscreve-se nos corpos e 'nas almas' dos sujeitos que a integram, (re)produzindo e modificando identidades. Desse modo, o gênero é tomado como um organizador explícito ou subjacente do processo de tornar-se cuidadora, na medida em que o cuidado aqui analisado é aprendido, exercitado e negociado, fundamentalmente, no âmbito de relações sociais de gênero. ${ }^{2-3}$

Por último, consideramos o cuidado como um encontro, ou uma série de encontros, entre dois ou mais indivíduos e de um indivíduo consigo mesmo, que toma como foco necessidades de saúde, mas vai muito além delas. ${ }^{5}$ Essa noção de cuidado permite "(re)conhecer, esclarecer e (re)construir" não apenas essas necessidades de saúde, mas aquilo que se entende "como sendo a Boa Vida e o modo moralmente aceitável de buscá-la" 1:550 o que se conecta, nessa perspectiva, à noção de felicidade: "experiências vividas, valoradas positivamente, [...] que, frequentemente, independem de um estado de completo bem-estar ou de perfeita normalidade morfofuncional" 1:551

Tendo apresentado o objetivo do artigo e delineado um 'modo de ver', passamos agora a descrever, brevemente, os procedimentos metodológicos realizados.

\section{PROCEDIMENTOS METODOLÓGICOS}

\section{Construindo modos de fazer}

A pesquisa na qual o material aqui analisado foi produzido caracteriza-se como exploratória- 
-descritiva, de abordagem qualitativa, e foi realizada na Clínica de Hemodiálise do Hospital de Clínicas de Porto Alegre/Rio Grande do Sul (instituição de natureza pública, geral e universitária que atende prioritariamente oSUS), no período de dezembro/2009 a fevereiro/2010. Foi aprovada pelo Comitê de Ética e Pesquisa do mesmo hospital, sob o número 09-279/julho/s009.

O trabalho de campo realizado envolveu a observação sistemática do funcionamento e das rotinas de trabalho e de assistência no espaço do serviço de hemodiálise. Envolveu, ainda, conversas informais e entrevistas em profundidade com os usuários que aceitaram fazer parte da pesquisa e que correspondiam a critérios de tempo em tratamento, contemplando doentes em processo inicial, médio e longo tempo. As entrevistas visibilizaram a centralidade das 'cuidadoras' nas vidas cotidianas dos doentes entrevistados. Isso nos levou a considerar a importância de ouvir as experiências de tais cuidadoras e, com elas, realizamos este trabalho, utilizando entrevistas semiestruturadas, contabilizadas em dez porque um doente tinha a filha e uma companheira que o cuidavam. As observações foram assinaladas em diários de campo e as entrevistas foram registradas em um gravador digital e transcritas, com a anuência formal dos/ as informantes. Os textos assim gerados foram examinados na perspectiva da análise cultural. Com esse procedimento de análise buscamos (re) conhecer e descrever alguns dos significados aos quais as informantes remeteram quando falaram de si e de suas vidas transformadas pela doença do outro, das relações que estabelecem consigo mesmas, com o ser cuidado e com as instituições sociais com as quais interagem. ${ }^{6}$ Nesse sentido, um dos exercícios que fizemos foi problematizar a homogeneidade, a essencialização e a universalidade contidas, por exemplo, em termos como 'tudo', 'cuidado', 'doença' e 'dependência', entre outros, para tornar visíveis alguns mecanismos e certas estratégias de poder que instituem e legitimam essas noções, delimitando, assim, possibilidades de se (re)definir identidades e relações de poder no contexto da doença renal crônica.

Os encontros com as mulheres cuidadoras foram solicitados e agendados por intermédio dos doentes renais crônicos. Através deles encaminhamos, também, os termos de consentimento livre e esclarecido, com todas as informações sobre o estudo e a solicitação para participação, considerando a vontade e a disponibilidade delas. Inicialmente, solicitamos que as entrevistas acontecessem na residência das cuidadoras, para que fosse possível tanto ter uma visão mais ampla dos seus contextos de vida quanto garantir certo conforto a elas, na medida em que não haveria custos de deslocamento para realização das entrevistas. Todavia, com exceção de duas, todas as outras cuidadoras preferiram que as entrevistas acontecessem em locais públicos. Para a recusa, alegaram "ser melhor" para elas, que "moram muito longe" ou que "não teriam horário disponível porque trabalham". Duas cuidadoras que moram em uma cidade vizinha a Porto Alegre aceitaram que uma de nós fosse até sua cidade para a entrevista, mas solicitaram que o encontro acontecesse em um local público ou no seu local de trabalho, não em suas residências.

As cuidadoras entrevistadas - todas adultas, sendo uma com mais de 60 anos e uma com menos de 25 - estão vinculadas afetivamente aos doentes renais crônicos em tratamento hemodialítico. Dessas dez mulheres, uma é mãe, trabalha fora de casa e assume os cuidados do filho doente, da casa, do marido e dos outros filhos; outra é filha de um dos doentes, é enfermeira, vive na mesma residência do pai (este tem, há muitos anos, uma companheira com quem não divide a mesma unidade doméstica, e é a filha que assume o encargo de cuidadora mais próxima). Todas as outras são companheiras e esposas.

As cuidadoras foram numeradas conforme a identificação dos doentes da pesquisa original, seguindo a ordem da realização das entrevistas, que foi aleatória. A forma gráfica de apresentação escolhida foi um ' $c$ ' minúsculo, que a identifica como cuidadora, acompanhado do número que lhes foi atribuído na organização das entrevistas.

Nas entrevistas com as mulheres, a pergunta inicial foi: o que mudou em sua vida com a doença do familiar que agora você cuida?

\section{RESULTADOS E DISCUSSÃO}

\section{'Elas', na perspectiva 'deles', de si mesmas e das pesquisadoras}

Durante as sessões de hemodiálise que acompanhamos, quase sempre surgiam, nos diálogos estabelecidos com os doentes, comentários sobre a importância das cuidadoras em suas vidas. Para eles, elas representam a sustentação e a manutenção de seus cotidianos. Com o desenrolar da doença e do tratamento do homem, agora doente, ao qual elas prestam cuidados, elas se constituem como mulheres cuidadoras, adaptando-se a outras 
formas de vida que decorrem da evolução da doença deles e da necessidade de atenção/cuidados que essa evolução impõe a elas.

Isso vai ao encontro de estudos ${ }^{7}$ em que se constatou que: é a família - e dentro dela as mulheres - que habitualmente assume, em maior proporção, a responsabilidade pelos cuidados domiciliares que as pessoas dependentes necessitam; as cuidadoras são, em geral, companheiras e esposas que residem com o doente, assumindo os encargos da casa e, algumas delas, trabalhando fora do lar, tornam-se também suas provedoras; várias cuidadoras se encontram na faixa de meia idade ou são idosas jovens, além de donas de casa que têm uma ligação afetiva mais estável e permanente com a pessoa que necessita de seus cuidados; $\mathrm{o}$ ato de cuidar e ser um familiar requer muito desprendimento e paciência, já que, muitas vezes, apenas um único membro da família assume o cuidado do doente. ${ }^{8}$ Esse conjunto de características usualmente implica um maior compromisso com o cuidado e um vínculo de atenção integral, tanto prático como emocional.

As entrevistadas assumem, quase sempre, todo o cuidado pessoal, com o tratamento e com as atividades cotidianas e sociais que esses homens demandam. Por exemplo: das nove cuidadoras que vivem no mesmo domicílio com os homens deste estudo, oito os acompanhavam até a unidade de diálise no início do tratamento e ficavam esperando até o final da sessão para levá-los para casa, sempre 'alertas' a qualquer alteração que pudesse acontecer durante o procedimento. Fora da unidade de tratamento, elas também zelavam pela segurança dos doentes no retorno a suas residências, tornando-se, assim, imprescindíveis ao processo de adaptação à diálise e atentas aos sintomas pós-procedimento, ao menos até estes não estarem mais tão presentes. Tal conduta é assumida por elas nos primeiros meses do tratamento. Â medida que eles se adéquam ao tratamento e conseguem organizar suas idas e vindas da clínica, algumas cuidadoras passam a não acompanhá-los mais de forma tão efetiva, porém adaptam suas outras atividades de modo a não se afastarem demasiadamente do hospital durante o período da diálise. Ficar sentada na sala de espera da diálise por três a quatro horas, três dias por semana, não é considerado, por algumas, como um ato proveitoso: [...] ficar no meio daquelas mulheres lá eu não gosto. Dessas mulheres dos maridos lá, eu não gosto, elas têm uma cabeça deste tamanhinho, ficam ali fazendo crochê e falando do marido, que não comeu isso, que não comeu aquilo, que não comeu aquilo outro. Ah, é horrível, eu sei, às vezes eles não querem dar esse trabalho [...] (c3). Essa convivência, que para algumas pode ajudar na compreensão da situação de seus 'dependentes', para outras pode gerar grande ansiedade, justamente pela identificação e pelo julgamento comuns ao quadro desencadeado pela doença.

Dentre os cuidados diretos assumidos pelas cuidadoras estão: garantir a alimentação, o acesso à medicação, a ajuda para se vestir, a proteção e o auxílio na recuperação após o procedimento. Outras formas de cuidado podem ser consideradas mais complexas, como a manutenção do lar, da convivência familiar, em grupo e social. Dependendo de como voltam para casa após um procedimento dialítico, os homens podem necessitar de ajuda em atividades mínimas e elementares para seu bem-estar, o que muitas vezes pode representar uma dificuldade para a preservação da noção que eles têm da própria dignidade. A maioria das cuidadoras afirma, no entanto, que a dependência do doente nunca é total e geralmente é vista como temporária. Os problemas de adaptação e vários outros, decorrentes do tratamento, podem ocorrer a qualquer momento, devido a todas as alterações hemodinâmicas pelas quais o doente passa, o que pode exigir que a cuidadora mantenha-se em estado de alerta: [...] eu já aprendi agora. Ele tem que botar uma bolsa quente. Vamos botar uma bolsinha quente? Então, agora ele chega da hemodiálise, eu já deixo uma bolsa quente do lado dele, e pronto [...] (c2).

\section{"A doença renal crônica mudou tudo em minha vida" - multiplicando significados do termo 'tudo'}

À pergunta inicial 'O que mudou em sua vida com a doença do familiar que agora você cuida?', a resposta de quase todas as entrevistadas foi: tudo. O significado literal desse tudo é o de totalidade das coisas. $\mathrm{O}$ vocábulo, porém, pode ser compreendido através de outra acepção: a de múltiplas mudanças, em diferentes tempos, que podem ter constituído outras trajetórias identitárias para essas cuidadoras.

O tempo, na vida das pessoas, pode ser visto como uma construção de suas experiências, como o agrupamento mais ou menos organizado dos fatos que nos acontecem e são interpretados em uma experiência de articulação temporal. ${ }^{9}$ As mudanças na maneira de viver dessas mulheres com a instauração da doença parecem ser avalia- 
das de modo muito mais severo do que seriam em um período 'de saúde'. Ainda assim, é notável a maneira como elas se reconstroem e se adaptam ao novo contexto.

Voltando ao termo tudo, elegemos alguns elementos que podem ser constitutivos dele, para fins de análise. Digamos que ele pode estar diretamente relacionado, por exemplo, ao impacto na saúde física e mental, ao peso da dependência do outro e à reconfiguração necessária das relações afetivas e sexuais. A seguir, veremos em detalhes os diversos significados que a palavra tudo pode assumir nos discursos das cuidadoras.

\section{Impacto na saúde física e mental}

'Doença crônica' é um termo clínico, "uma construção do saber biomédico" ${ }^{10: 10}$ que está relacionado à impossibilidade de resolução de um problema de saúde. A doença crônica é caracterizada, com muita frequência, como um acontecimento que altera e gera muito estresse ao doente e a todos os componentes de sua família, especialmente às pessoas que assumem o cuidado que ela, a doença, demanda. A família, ao vivenciar as modificações que a doença crônica desencadeia em seu espaço de convivência, "experimenta inicialmente um desequilíbrio em sua capacidade de funcionamento normal, [provocado por] alterações que envolvem afeto, finanças e relações de poder que levam a um processo de reorganização familiar". 11:16

O doente renal crônico, em especial, ao tornar-se dependente de uma filtração extrarrenal de seu sangue para viver, passa por alterações significativas em seu modo de viver e de 'ser'. Suas cuidadoras também. O impacto pode ser tão grande que, segundo algumas, somente um profissional como o psicólogo pode auxiliá-las, já que essas alterações atingem a vida dos(as) envolvidos(as) em todos os níveis: social, familiar e profissional até o plano pessoal/psíquico.

As mulheres falam dessas alterações das mais diversas maneiras. Para algumas, a alteração do humor desses doentes, muito presente no início do tratamento hemodialítico, é algo difícil de enfrentar. Segundo elas, esse componente - que, segundo algumas, melhora um pouco com o tempo - torna a convivência diária quase insuportável. De acordo com o depoimento de uma cuidadora, o familiar doente sempre foi um homem de temperamento muito forte, teimoso, bravo, rebelde [...](c1). Tais características acentuaram-se com a doença. Em vista disso, ela agora tinha que ser muito mais incisiva para manter o controle de diversas situações do seu cotidiano. Essa postura, com o passar dos anos, levou a cuidadora à exaustão. Ela diz que está muito, muito cansada e que agora tem acompanhamento psiquiátrico, pois, sem esse apoio, não aguentaria todas essas mudanças. Reforçando a fala de c1, outra cuidadora coloca: ah, mas no começo foi bem boca braba. Era o que ele dizia, era o que ele falava... Eu disse 'Bah, mas eu não vou conseguir, se ele ficar assim desse jeito, né. Como é que eu vou conseguir, ele agressivo, agressivo, agressivo' [...]. Mas foi indo, foi indo, foi indo, agora, graças a Deus, ele está bastante mudado, bastante mesmo. Tá bem mais calmo (c3). Esta mulher também faz acompanhamento psiquiátrico.

Procurar acompanhamento psiquiátrico parece ser uma das estratégias para o enfrentamento da doença utilizadas pelas cuidadoras de doentes renais crônicos. Mesmo estando em condições econômicas desfavoráveis, muitas optam por esse acompanhamento como forma de manter o equilíbrio e seguir ao lado daquele que necessita de seus cuidados. A exigência dos cuidados informais tem efeitos negativos sobre a saúde, tanto física quanto psíquica, do cuidador. É comum que essas pessoas, no decorrer do tempo, comecem a sofrer esgotamento físico e mental, problemas fisiológicos e estados depressivos associados a sentimentos de impotência e resignação. ${ }^{7}$

O relato da cuidadora c3 dimensiona bem a instabilidade emocional a que esses doentes renais crônicos estão sujeitos, e essa instabilidade, em função da convivência diária muito próxima e intensa, acaba impactando fortemente sua saúde psíquica. A doença produz alterações fisiológicas contínuas, para as quais há poucas possibilidades de intervenção que apresentem resultados imediatos e satisfatórios. Assim, o impacto da enfermidade tem que ser trabalhado dia a dia, e novos caminhos geralmente devem ser construídos para se conduzir a vida, agora cercada de muitas incertezas. ${ }^{10}$

\section{Peso da dependência do outro}

Todas as entrevistadas disseram que vivem em função de seus doentes, visto que muitos realmente dependem delas para sua sobrevivência durante o tempo em que realizam se encontram em diálise. Alguns problemas práticos, ligados às alterações físicas sofridas pelo paciente, podem ser solucionados de maneira temporária, chegando a estabilizar-se; outros podem permanecer e até agravar-se durante o tempo de vida da pessoa doente. 
No presente estudo, tivemos contato com mulheres que cuidam desses homens há alguns meses e outras que o fazem há mais de dez anos. Uma delas, que faz parte do segundo grupo, afirma que, depois de tanto tempo em tratamento, ela e o doente não vivem mais, vegetam (c1). A mesma cuidadora diz ainda, sem reservas, que não sabe mais o que é felicidade, que sua paciência não existe mais e que nada faz para se distrair a não ser dormir quando o doente vai para diálise (três vezes por semana, por um período de três a quatro horas). Tal situação, no contexto analisado, está longe de ser incomum: "independente do tipo de cuidado prestado, com o tempo essa tarefa torna-se árdua e complexa, podendo gerar em determinadas situações sentimento de angústia, insegurança e desânimo". 12:1286

O peso da dependência, no âmbito da doença crônica, atinge paciente, cuidadora e familiares de muitas formas. Uma das entrevistadas, por exemplo, perdeu o emprego de balconista por conta do compromisso assumido com o 'seu' doente, depois de trabalhar por muitos anos em uma empresa no aeroporto, cumprindo rigorosamente tudo que lhe era solicitado. Priorizava o trabalho, mesmo com o filho pequeno, que ficava na escolinha ou com vizinhos, quando a empresa precisava dela. Um dia viu-se na situação de cuidadora do marido doente. O problema dele se complicou e ela, cada vez com maior frequência, precisou fazer trocas de turnos com colegas no seu trabalho para conseguir acompanhar o marido, dependente de sua presença. Na pragmática avaliação da empresa em que trabalhava, os compromissos que ela tinha que assumir eram muitos e seus problemas tinham pouca chance de serem resolvidos a curto prazo. O resultado foi a demissão.

A impossibilidade ou a diminuição do acesso ao trabalho remunerado, assim como o aumento 'desmesurado' da carga de trabalho em casa é considerado por alguns autores como uma das consequências a que estão submetidas mulheres que assumem o cuidado e a manutenção da vida de familiares doentes. ${ }^{7} \mathrm{O}$ afastamento do mercado de trabalho é, em geral, acompanhado da falta de redes sociais de apoio formal. A narrativa da cuidadora citada reforça essas colocações: os anos de trabalho e sua postura profissional dedicada não importaram muito no momento em que surgiu a situação pontual da doença. A única rede de apoio com que contava era a das vizinhas, para cuidar de seu filho quando este saía mais cedo da escola, antes que ela conseguisse chegar em casa. Na situação de doença de seu marido, foi ela que teve que reorganizar sua vida para poder atendê-lo. E aqui é possível perceber que mesmo as redes 'informais' de suporte a cuidadoras - geralmente formadas por outras mulheres, que assumem parte de tarefas cotidianas, tais como buscar, levar ou permanecer com as crianças enquanto as mães trabalham fora do lar, por exemplo - não dão conta da complexidade da demanda de cuidado que se instala com a doença renal crônica. Com o tempo, essa dependência do outro, com as impossibilidades que ela produz, pesa, como elas dizem.

Entretanto essa dependência que é vivida como um peso também implica modificações das relações de poder de gênero vigentes em alguns contextos culturais, como sinaliza uma entrevistada: ele não sabe nem a medicação que toma, ele não sabe, até brinco com ele: 'se eu te der veneno, tu toma'. Eu só dou o remédio, ele abre a boca e toma [...] (c9)

\section{Reconfiguração necessária das relações afetivas e sexuais}

Pode-se dizer que nem a vida sexual das cuidadoras de doentes renais crônicos escapa às consequências da doença e do tratamento. O doente renal crônico pode apresentar um quadro de disfunção sexual de difícil ou nenhuma reversão e isso pode, muitas vezes, interferir em suas relações afetivas. Algumas das entrevistadas, como c1, sinalizaram que é possível, mesmo em face da doença, encontrar algumas formas de satisfação sexual; outras, como c9, resignam-se com o fato, colocando-o como algo de pouca importância.

A mesma cuidadora que afirmou que dormir era sua única distração enquanto seu marido ia para diálise, mais tarde, quando perguntada a respeito de sua vida sexual, fez outra colocação: disse que, com o tempo, encontrou novas formas de prazer com o companheiro. Quando estão sozinhos em casa, depois de fechar portas e janelas, ela e o esposo vão tomar banho juntos, ficam no seu cantinho e brincam o tempo todo, o que considera muito bom (c1). Refere ainda que, na hora de dormir, os dois mantêm o hábito de ficar com as pernas entrelaçadas, e que nunca dormiu separada dele. Ela dimensiona, assim, uma maneira de (re) configurar a relação afetivo-sexual e manter o prazer do convívio.

Aspectos diferentes emergem na fala de outra cuidadora, igualmente questionada acerca de sua vida sexual. Ela e o marido tinham vida sexual satisfatória até iniciar a hemodiálise, depois não tiveram mais: não, não adianta tentar, não faz nada 
(c8). Esse fato leva muitas pessoas a questioná-la sobre sua necessidade sexual:

[...] Até tem gente que me critica, sabe, que eu tenho que mudar. Até o psicólogo que eu fui, fiquei com vergonha até [sugerindo a possibilidade de outras formas de satisfação sexual]. Mas eu acho que não, eu acho que se eu não fiz nada para ele enquanto ele era são, porque eu vou fazer agora que ele é doente? Eu não acho justo. E também não tenho, não passa assim pela minha cabeça, eu não tenho vontade de me envolver com alguém, que eu vou arrumar mais um problema para mim. Deus me livre, se ele fica sabendo, alguma coisa, e eu, na verdade, eu não sinto tanta falta, apesar de ter perdido muita coisa. Já tenho cinquenta e três anos, eu já tô velha. E a gente viveu muito bem, ele sempre foi um homem muito trabalhador, uma pessoa muito honesta, sempre procurando dar o melhor pra mim, pra nós [...] (c8).

A fala destacada remete a outra entrevistada (c9), para quem o que parece importar é o laço de família que deve ser mantido, pois seria o mais importante. Assim, ela conta que a vida sexual deles parou completamente e que ele ficou quase louco, mas que ela estava tri bem. Ficou normal pra mim, diz ela, reforçando que, do seu ponto de vista, tal aspecto não tem sido vivido como um limite. Ainda segundo ela, a mulher aguenta mais... e ele agora nem fala mais [sobre o assunto], mesmo que o médico tenha dito que ele devia tentar uma medicação para acabar com a disfunção erétil. Essa cuidadora tem 60 anos e é sete anos mais velha que o marido/companheiro. O estar tri bem, mencionado, assim como a referência anterior de que já tenho 53 anos... já tô velha, podem estar constituídos por uma representação cultural e científica de sexualidade feminina depois da menopausa. Em conjunto, as duas falas remetem a representações de sexualidade masculina e feminina naturalizadas no âmbito de nossa cultura, que se expressam em frases como eu não sinto tanta falta, a mulher aguenta mais e ele ficou quase louco (c9). Estão operando aí representações relacionais de gênero e sexualidade que reiteram uma dada natureza feminina para a qual o sexo não faz tanta falta, ou que consegue mais facilmente refrear e controlar sua sexualidade do que alguém com uma natureza masculina, dotada de sexualidade definida como impulso, quase impossível de controlar ${ }^{3}$ e que também continua muito ativa em práticas educativas informadas por discursos da área da saúde.

Entretanto o que emerge de entrevistas como as realizadas com c1, c3, c6, c8 e c9 é a preocupação e o desejo de viabilizar a manutenção de uma vida em comum, com a preservação da família e das relações de afeto construídas antes da doença. Essa preocupação leva as mulheres a reorganizarem muitas formas de pensar e agir, no sentido de preservar o 'respeito' ao homem viril e provedor que conheceram antes da doença, ainda que tal preservação implique uma ambivalência de sentimentos muito visível em um dos excertos: Deus me livre, se ele fica sabendo [...] ele sempre foi um homem muito trabalhador [...] sempre procurando dar o melhor pra mim [...] (c8).

Uma entrevistada relata que viveu com grande intensidade a ambivalência de sentimentos desencadeada pela doença em associação com outras experiências anteriores vinculadas à descoberta de uma traição no contexto de uma relação de amor enorme com esse homem, agora doente. Ela parece ter encontrado, na relação de cuidado e em tudo que ela demanda, uma maneira legítima de manter o afeto por ele, e ficou a seu lado. Ela foi uma das mulheres que aceitou fazer a entrevista em casa e procurou demonstrar, em quase todos os momentos da conversa, que agora era ela a pessoa forte que mantinha a relação e, para isso, investia muito no reforço da autoestima do companheiro, a fim de poderem seguir com o tratamento e com suas vidas: [...] eu não acho ele um coitadinho, eu não trato ele como coitadinho, entendeu? 'Ai, pobrezinho do meu velho'. Não, eu trato ele normal, é a vida que nós temos que viver. Nós temos que tocar o nosso barco, nós temos que ir para frente [...] (c3).

Em determinadas etapas de suas vidas, pela urgência demandada por fatos e acontecimentos vinculados a mudanças bruscas na vida familiar, mulheres podem ser levadas a aceitar e a assumir situações que deixam muito pouco espaço para escolhas. ${ }^{13}$ Tais situações, acrescentamos nós, convergem com representações de gênero culturalmente disponíveis para determinados grupos sociais. Nessa convergência, por exemplo, preservar a relação afetiva em meio a tantas reestruturações e problemas inesperados que a doença demanda é muito importante para elas, como indivíduos, mas é também o que se espera que elas façam, como mulheres. E, nessa conflitualidade, essa convergência pode ser vivida como uma forma de valoração dessas experiências que independem de um 'estado de completo bem-estar', como sinaliza a noção de felicidade com que iniciamos o artigo. ${ }^{1}$ Mesmo não sendo a situação ideal, a satisfação e a responsabilidade da manutenção dessa relação são vividas em determinados grupos sociais como um 'ato de nobreza'. ${ }^{12}$ 


\section{CONSIDERAÇÕES FINAIS}

Para as mulheres entrevistadas neste estudo, 'tornar-se' cuidadora de um doente renal crônico implicou, a construção de outras identidades, mas, de forma recorrente, as falas aqui analisadas estão relacionadas - de forma explícita ou subliminar ao cuidar conjugado no feminino. E esse cuidar, como relação que é, implica reconfigurações identitárias contínuas e conflituosas tanto das mulheres quanto dos homens que estão imersos em tal situação, uma vez que a construção de uma identidade cuidadora se faz em conexão com a construção de uma outra identidade - a que demanda cuidado.

Assim, ser uma pessoa respeitosa, zelosa e carinhosa são qualidades apontadas como importantes por algumas cuidadoras entrevistadas. Para estas, tais qualidades parecem fazer parte de sua obrigação, como mulher, para com o doente e tudo que o cerca: há uma tarefa a ser cumprida e ela tem que ser feita. O remédio, o alimento, o conforto e tudo que envolve cuidar e manter a vida dessa pessoa implica, também, estar constantemente disponível. Nesse sentido, estão em jogo relações sociais, familiares e/ ou conjugais - e até mesmo profissionais - que envolvem mulheres e homens e nas quais se delineia o cuidado como destino. Um cuidado que engloba não só os indivíduos, mas também as 'coisas' que estão relacionadas com essas instâncias sociais e culturais, incluindo-se aí o cuidado com as roupas, com a comida, com a saúde, com a emoção, com a autoestima (além de uma infinidade de outros) dos homens - adultos e crianças - com quem essas mulheres convivem.

Assim, podemos dizer que as entrevistas aqui analisadas de certa forma reiteram as representações de gênero que instituem o cuidado como essência e como destino de certas mulheres. Essas representações podem ser encontradas, com algumas variações, em múltiplos campos do conhecimento que compõem o que, genericamente, chamamos de pensamento moderno ocidental. É uma dimensão também discutida, de formas nem sempre coincidentes, nas diferentes vertentes feministas da atualidade. Todavia ainda é possível dizer que, nesse processo de cuidar, essas mulheres ressignificam a si mesmas e, nesse movimento, ressignificam elementos dessas representações, no momento em que elas passam a ser, além de tudo, organizadoras e referências dessas vidas masculinas.

Como apontamos, a dependência dos homens doentes, significada como um 'peso' fun- ciona, ao mesmo tempo, como uma inversão da relação de poder de gênero usual, na medida em que eles passam a ser completamente dependentes delas. E assim também é possível dizer que, nessa relação de cuidado, ocorre uma ressignificação de alguns elementos constitutivos de representações de masculinidade hegemônicas em nossa cultura, produzindo-se, também, outras identidades masculinas.

Por isso, em seu conjunto, os excertos aqui analisados são indicativos da complexidade das relações de poder que, no âmbito da cultura, atuam para configurar, de determinados modos, as relações sociais de cuidado no contexto da doença renal crônica. Tais relações, ao mesmo tempo em que possibilitam que determinados tipos de cuidado sejam operacionalizados, também produzem, normatizam e controlam formas e 'lugares' nos quais mulheres e homens específicos vivem suas vidas conjuntas ou separadas; formas pelas quais elas e eles se relacionam, vivem e regulam suas vidas, seus conflitos e seus confrontos. Desse modo, a presente análise indica, ainda, que essas dimensões sociais e culturais precisariam ser mais consideradas em estudos que pretendam dar conta da complexidade das relações de cuidado.

\section{REFERÊNCIAS}

1. Ayres JR. Hermenêutica e humanização das práticas de saúde. Ciênc Saúde Coletiva. 2005 Jul-Set; 10(3):549-60.

2. Louro G. Currículo, gênero e sexualidade - o "normal", o "diferente" e o "excêntrico". In: Louro G, Neckel JF, Goellner, SV, organizadores. Corpo, gênero e sexualidade: um debate contemporâneo na Educação. Petrópolis (RJ): Vozes; 2005. p.41-52.

3. Meyer DEE. Teorias e políticas de gênero: fragmentos históricos e desafios atuais. Rev Bras Enferm. 2004 Jan-Fev; 57(1):13-8.

4. Silva TT. O currículo como fetiche. A poética e a política do texto curricular. Belo Horizonte (MG): Autêntica; 1999.

5. Ayres JRM. Cuidado e reconstrução das práticas de saúde. Interface - Comunic. Saude Educ. 2004 Set-Fev; 8(14):73-92.

6. Wortmann ML. Algumas articulações entre estudos culturais e educação. In: Silveira RM, organizador. Cultura, poder e educação. Canoas (RS): Ed. da Ulbra; 2005.

7. Bover A. Cuidadores informales de salud del ámbito domiciliario: percepciones y estrategias de cuidado ligadas al género y a la generación [tese]. Palma de Mallorcs (ES): Universitat des les Illes Balears, Departament de Ciències de l'Educació; 2004. 
8. Sant'Ana MM, Pereira VP, Borenstein MS, Silva AL. O significado de ser familiar cuidador do portador de transtorno mental. Texto Contexto Enferm [online]. 2011 Jan-Mar [acesso $2011 \mathrm{Jul}$ 17]; 20(1):50-8. Disponível em: http:/ /www.scielo. $\mathrm{br} /$ scielo.php?script $=$ sci_arttext\&pid=S010407072011000100006\&lng=pt

9. Larrosa J. Notas sobre a narrativa e identidade. In: Abrahão MHMB, organizador. A Aventura (auto) biográfica: teoria \& empiria. Porto Alegre (RS): EDIPUCRS; 2004.
10. Canesqui AM, organizadora. Olhares socioantropológicos sobre os adoecidos crônicos. São Paulo: Hucitec; Fapesp; 2007.

11. Karsch U. Idosos dependentes: famílias e cuidadores, Cad Saúde Pública. 2003 Mai-Jun; 19(3):861-66.

12. Ribeiro MTF, Ferreira RC, Ferreira E, Magalhães CS, Moreira AN. Perfil dos cuidadores de idosos nas instituições de longa permanência de Belo Horizonte, MG. Ciênc Saúde Coletiva. 2008 Jul-Ago; 13(4):1285-92.

13. Alberoni F. Enamoramento e amor. Rio de Janeiro (RJ): Rocco; 1988. 